\title{
A Survey on the Access, Acceptability and Implementation of Dyslipidemia Guidelines among Physicians in Malang, Indonesia
}

\author{
Putu Arsana, Rulli Rosandi, Heri Sutanto, Achmad Rudijanto, Herman Trianto \\ Endocrinology \& Metabolic Disease Division, Internal Medicine Department Brawijaya University \\ Saiful Anwar General Hospital Malang, Indonesia
}

\begin{abstract}
Objective. The implementation of guidelines in clinical practice is still facing a lot of obstacles. Although clinical recommendations of dyslipidemia are extant, little is known about how community physicians view guidelines and their implementation. The objective of this study is to assess the acceptance of guideline content and perceived implementation of dyslipidemia guidelines among physicians in Malang, Indonesia.
\end{abstract}

Methodology. Semi-structured validated questionnaires were given to 67 random physicians consisting of general practitioners (GP), internal medicine residents and internists. The questionnaire consisted of 19 questions evaluating four parts: information about access to dyslipidemia training, dyslipidemia guideline-perceived knowledge, level of understanding of dyslipidemia guidelines and application rate of guideline adopted. Evaluation results were scored ordinally and divided into 3 levels; less, enough and good for each part of the questionnaire.

Results. $89.2 \%$ of samples in the GP group lacked information about dyslipidemia training. The resident group had participated and were involved in dyslipidemia management training (98.3\%), followed by the internist group $(95.2 \%)$. In the GP group, $89.2 \%$ never or had less participation in dyslipidemia management training. The GP group (76.2\%) also had had poor knowledge in understanding lipid guidelines, in which the least knowledge is known about targets of treatment, non-drug treatment and risk factors. Also, $40.3 \%$ of the GP group is still not capable of adopting dyslipidemia guidelines in daily practice. A major barrier was lack of understanding of guidelines $(76.3 \%)$, followed by failure of adherence to the therapy of patients $(12.1 \%)$. In the resident group, a major obstacle in the application of the guidelines is education level of the patient (45.5\%). In all groups, HMG-CoA Reductase inhibitors are the most commonly used lipid-lowering drugs for treatment of dyslipidemia (98.1\% in GP group, $96.3 \%$ in resident group, and $97.3 \%$ in internist group).

Conclusions. GPs, as physicians in primary health care system, had poor information and participation in dyslipidemia training, and poor knowledge of dyslipidemia guidelines (AACE, AHA, CCS), as well as understanding and application of the dyslipidemia guidelines (ATP III, PERKENI) to the population, whereas residents and internists had better perception and application of dyslipidemia guidelines.

Keyword: Dyslipidemia, guideline, acceptance, physicians

\section{INTRODUCTION}

The most common fatal outcome of hypercholesterolaemia as a risk factor is coronary heart disease (CHD), now the leading cause of death worldwide. ${ }^{1-4} \mathrm{Up}$ to $25 \%$ of first myocardial infarctions are fatal, ${ }^{5-7}$ and the outcome for survivors is also serious, with a 10 year mortality rate of $37 \%$ for those with angina and 55\% for those suffering a myocardial infarction. ${ }^{8-10}$

Dyslipidemia is a primary, major risk factor for CAD and may even be a prerequisite for $\mathrm{CAD}$, occurring before other major risk factors come into play. ${ }^{4-6,8-14}$ Epidemiologic data also suggest that hypercholesterolemia

e-ISSN 2308-118X

Printed in the Philippines

Copyright (C) 2014 by the JAFES

Received April 30, 2014. Accepted October 27, 2014.

http://dx.doi.org/10.15605/jafes.029.02.04 and perhaps coronary atherosclerosis itself, are risk factors for ischemic stroke. . $^{4,10}$ Increasing evidence also points to insulin resistance which results in increased levels of plasma triglycerides and low-density lipoprotein cholesterol (LDL-C) and a decreased concentration of high-density lipoprotein cholesterol (HDL-C)-as an important risk factor for peripheral vascular disease, stroke and CAD. ${ }^{8-14}$

However, $69 \%$ of US adults have LDL-C concentrations above $100 \mathrm{mg} / \mathrm{dL}$. Furthermore, the doubling in the prevalence of persons who are obese and the high percentage of patients with elevated triglyceride levels (33\%) point to the need for continued vigilance on the part

Corresponding author: Herman Trianto, $M D$

Supervisor, Consultant of Endocrinology \& Metabolic Disease Division

Department of Internal Medicine, Faculty of Medicine

Brawijaya University - Dr. Saiful Anwar General Hospital

Jl. Jaksa Agung Suprapto 2, Malang, Indonesia 65111

Tel. No.: +62341-351445

Fax No.: +62341-351445

E-mail: drhermanbagustrianto@yahoo.com 
of physicians to reduce the risks of cardiovascular disease. ${ }^{5-7}$ Success rates for patients achieving US National Cholesterol Education Program (NCEP) LDL-C targets were $37 \%$ among high-risk patients and only $18 \%$ among patients with CHD. ${ }^{8}$ These findings are consistent with those from the Third National Health and Nutrition Examination Survey (NHANES III). ${ }^{5}$ Both studies found that over $80 \%$ of patients with existing CVD do not achieve target cholesterol levels.,

Guidelines attempt to define practices that meet the needs of patients in most circumstances. ${ }^{15}$ To explore this gap between evidence and practice in the prevention and management of dyslipidemia, this study was conducted. The two major objectives of the survey were to assess knowledge of dyslipidemia itself, and acceptance and/or implementation of treatment guidelines for dyslipidemia among physicians.

In Indonesia, this is one of few studies that were performed to investigate the disease burden and quality of care in dyslipidemia. The results would be important to improve the quality of dyslipidemia treatment and management in Indonesia.

\section{METHODOLOGY}

\section{Study Population and Questionnaire}

This survey was conducted in Malang, Indonesia. We recruited 67 physicians consisting of general practitioners (defined as primary care physicians or family doctors working for community in Malang), internal medicine residents (defined as physicians studying Internal Medicine Department at Saiful Anwar General HospitalBrawijaya University) and internists (defined as general internists working in various areas in Malang), by simple random sampling. Subjects were given a questionnaire that needed to be answered.

The questionnaire consisted of 19 questions evaluating four parts: information about access to dyslipidemia training, dyslipidemia guideline perceived knowledge, level of understanding of dyslipidemia guidelines and application rate of adopted guidelines. The evaluation was categorized into 3 level: less, enough and good. Answers about level of dyslipidemia training information were categorized as "less" if participants had no access to information at all, "enough" if participant had 1 information in the past 2 years, and "good" if participant had $>1$ information in the past 2 years. Answers about level of dyslipidemia training participation were categorized as "less" if participant had no training at all in the past 2 years, "enough" if participant attended 1 training in the past 2 years, and "good" if participant attended $>1$ training in the past 2 years (assuming there are changes in dyslipidemia guidelines within 2 years). Participants were also asked about guidelines known and adopted by them, which consisted of NCEP-ATP III
(National Cholesterol Education Program Adult Treatment Panel III), AACE (American Association of Clinical Endocrinologists), AHA (American Heart Association), CCS (Canadian Cardiovascular Society), and PERKENI (Indonesian Endocrinology Society).

Understanding adopted guideline consists of 9 questions, which covered knowledge about risk factors, target treatment, non-drug treatment and drug treatment. Participants were categorized as "less" if they answered < $30 \%$ of the questions correctly, "enough" if $31-60 \%$ of the questions were answered correctly, and "good" if $>60 \%$ of the questions were answered correctly. Application of adopted guideline consists of 5 questions. Participants were categorized as "less" if they answered $<30 \%$ of the questions correctly, "enough" if $31-60 \%$ of the questions were answered correctly, and "good" if $>60 \%$ of the questions were answered correctly.. The study was conducted from February through March 2014.

\section{Statistical Analysis}

A random sample of 67 physicians was estimated to capture the likely range of practice and opinion across physicians in each group: GPs, residents, and internists. For baseline characteristics, they were asked about mean years of practice, work place, and adopted guidelines. Type A hospital is defined as a hospital that is able to provide specialist and subspecialty medical care widely, Type B hospital is defined as a hospital that is able to provide specialist medical care widely and limited subspecialty medical care, Type $C$ hospital is defined as a hospital that is able to provide limited specialist care, consisting of internal medicine, surgery, pediatrics and obstetrics \& gynecology. Primary health care is defined as a first level of care or as the entry point to the health care system for consumers, and private clinic is defined as a health care facility funded by non-government institutions that is primarily devoted to the care of outpatients. ${ }^{16}$ Data are presented as response rates in percentage.

\section{RESULTS}

\section{Baseline Characteristics}

A total of 67 physicians were interviewed using a questionnaire. The general physicians (GP) group consisted of 19 subjects, the resident group consisted of 33 subjects and the internist group consisted of 15 subjects. Demographic characteristics of the physicians are given in Table 1.

Mean years in practice for the GP group was 9.7 years, for the resident group was 2.2 years and for the internist group was 5.3 years. Most of those in the GP group worked in primary health care $(90.9 \%)$, whereas all subjects in the resident group worked at a teaching hospital (Type A hospital) (100\%). Most of those in the internist group worked at type $\mathrm{C}$ hospitals. The guideline 
adopted mostly by the GP group is PERKENI Guideline (75.9\%), whereas resident group chose ATP III guideline (67.4\%) and internist group preferred ATP III (65.5\%) and PERKENI Guideline (34.5\%), respectively.

Table 1. Physician demographics

\begin{tabular}{lllll}
\hline & Total & GP & Resident & Internist \\
\hline Physicians & 67 & 19 & 33 & 15 \\
Male (\%) & 43.2 & 34.2 & 44.3 & 37.4 \\
Mean Years in practice & 6.3 & 9.7 & 2.2 & 5.3 \\
(years) & & & & \\
Work Place (\%) & & - & 100 & - \\
Type A Hospital & & 3.4 & - & 34.7 \\
Type B Hospital & 5.7 & - & 65.3 \\
Type C Hospital & 90.9 & - & - \\
Public Health Center & - & - & - \\
Private Clinic & & & \\
Adopted Guideline (\%) & & 24.1 & 67.4 & 65.5 \\
ATP III & & - & - & - \\
AACE & & - & 12.3 & - \\
AHA & - & - & - \\
CCS & & 20.3 & 34.5 \\
Perkeni & & 75.9 & &
\end{tabular}

\section{Dyslipidemia Training Information and Participation}

Lack of information of lipid treatment training was most common in the GP group with $(89.2 \%)$ versus only $1.2 \%$ of the internist group (Table 2). Apparently, the resident group participated well and were involved in Dyslipidemia Management Training, followed by internist group (95.2\%). In the GP group, 89.2\% never or had less participation in Dyslipidemia Training Management (Table 3).

\begin{tabular}{cccc}
$\begin{array}{l}\text { Table 2. Dyslipidemia } \\
\text { physician }\end{array}$ & training & information & among \\
\hline $\begin{array}{c}\text { Level of Dyslipidemia } \\
\text { Training Information (\%) }\end{array}$ & GP & Resident & Internist \\
\hline Less & 89.2 & - & 1.2 \\
Enough & 10.8 & 23.4 & 3.6 \\
Good & - & 76.6 & 95.2 \\
\hline
\end{tabular}

\begin{tabular}{cccc}
\multicolumn{3}{l}{ Table 3. Dyslipidemia training participation } & \\
\hline $\begin{array}{c}\text { Dyslipidemia Training } \\
\text { Participation (\%) }\end{array}$ & GP & Resident & Internist \\
\hline Less & 23.4 & - & - \\
Enough & 76.6 & 1.7 & 4.6 \\
Good & - & 98.3 & 95.4 \\
\hline
\end{tabular}

\begin{tabular}{cccc}
\multicolumn{4}{l}{ Table 4. Understanding adopted guideline } \\
$\begin{array}{c}\text { Understanding Adopted } \\
\text { Guideline (\%) }\end{array}$ & GP & Resident & Internist \\
\hline Less & 76.2 & - & 1.3 \\
Enough & 23.8 & 34.2 & 32.2 \\
Good & - & 65.8 & 66.5 \\
\hline
\end{tabular}

\section{Understanding of Adopted Guideline}

Of the GP group, $76.2 \%$ had poor knowledge in understanding lipid guidelines, with the least knowledge in target treatment, non-drug treatment and risk factors, respectively. It is not suprising that $66.5 \%$ of the internist group achieved good understanding of guidelines, however, some of them $(1.4 \%)$ had less understanding of non-drug treatment. The majority of subjects in the resident group $(65.8 \%)$ already understood lipid guidelines. Information is shown in Tables 4 and 5 .

\section{Application of Adopted Guideline}

Of the GP group, $40.3 \%$ of physicians were not capable of adopting dyslipidemia guidelines in daily practice, $59.7 \%$ were categorized as "enough" with none of them categorized as "good." On the contrary, resident group $(92.6 \%)$ as well as the internist group (94.8\%). had applied the guideline in clinical practice properly (Table 6).

Table 6. Application adopted guideline

\begin{tabular}{cccc}
\hline Application Adopted Guideline (\%) & GP & Resident & Internist \\
\hline Less & 40.3 & - & - \\
Enough & 59.7 & 7.4 & 5.2 \\
Good & - & 92.6 & 94.8 \\
\hline
\end{tabular}

\section{Barriers to Implementing Dyslipidemia Guideline Treatment}

In the GP group, a major barrier was lack of understanding of guidelines $(76.3 \%)$, followed by failure of adherence to the therapy of patients $(12.1 \%)$. In the resident group, a major obstacle in the application of the guidelines is the patient;s education level (45.5\%). Lack of patient adherence $(66.7 \%)$ plays a role in lipid therapy failure in the internist group (Table 7).

\begin{tabular}{lccc}
\multicolumn{4}{c}{ Table 7. Barriers to implementing guideline } \\
\hline \multicolumn{1}{c}{ Barriers (\%) } & GP & Resident & Internist \\
\hline Physician understanding & 76.3 & 1.5 & 2.1 \\
for lipid treatment & & & \\
Patient compliance & 12.1 & 34.2 & 66.7 \\
Patient Education & 6.1 & 45.5 & 12.5 \\
Polipharmacy & 3.4 & 16.2 & 10.4 \\
Cost & 2.1 & 2.6 & 8.3 \\
\hline
\end{tabular}

\section{Drug Prescribing}

In all groups, HMG-CoA reductase inhibitors are the most often used lipid-lowering drugs for treatment of dyslipidemia $(98.1 \%$ in GP group, $96.3 \%$ in Resident group, and $97.3 \%$ in Internist group). Fibric acid

Table 5. Understanding component in adopted guideline (\%)

\begin{tabular}{|c|c|c|c|c|c|c|c|c|c|}
\hline & \multicolumn{3}{|c|}{ GP } & \multicolumn{3}{|c|}{ Resident } & \multicolumn{3}{|c|}{ Internist } \\
\hline & Less & Enough & Good & Less & Enough & Good & Less & Enough & Good \\
\hline Risk Factor & 34.2 & 45.2 & 20.6 & - & 33.2 & 66.8 & - & 2.5 & 97.5 \\
\hline Target Treatment & 67.3 & 32.7 & - & - & 34.5 & 65.5 & - & 2.9 & 96.1 \\
\hline Non Drug Treatment & 34.5 & 21.4 & 44.1 & - & 4.5 & 95.5 & 1.4 & 2.6 & 96.0 \\
\hline Drug Treatment & 1.2 & 3.1 & 96.7 & - & 7.9 & 92.1 & - & 3.4 & 96.6 \\
\hline
\end{tabular}


derivatives are also used as an alternative to lipid therapy in a minority. (Table 8)

\begin{tabular}{|c|c|c|c|}
\hline Drug (\%) & GP & Resident & Internist \\
\hline HMG-CoA reductase & 98.1 & 96.3 & 97.3 \\
\hline Fibric Acid derivatives & 1.9 & 3.7 & 2.7 \\
\hline Bile acid sequestrants & - & - & - \\
\hline Nicotinic Acid & - & - & - \\
\hline
\end{tabular}

\section{DISCUSSION}

As with most surveys, this study's main limitations relate to the reliability and generalizability of the physician responses. The varied response rates of physicians in different groups (GP, Resident and Internist) might be due to more interested or more aware practitioners responding. There is also no mechanism to validate the physician responses, and how physicians may answer the questionnaire might not be how they actually practice. Despite such limitations, the sample of physicians was selected randomly, a good number of participants were collected across three groups, and the findings are important and relevant even if they are not entirely generalizable. ${ }^{15,17,19}$

Successful implementation of CVD prevention relies heavily on the primary care physician providing risk factor evaluation, intervention and patient education. ${ }^{15}$ The results of this study show that majority of primary care physicians (those in GP group) did not have sufficient information and poorly understood dyslipidemia guidelines aimed at reducing CVD risk factors. Aside from a lack of information about dyslipidemia training, access to attend the training is limited for GP group. But from our results, some physicians joined metabolic disease training consisting of diabetes and comorbid diseases including dyslipidemia management. Based on previous studies, this happens because GPs mostly work in primary levels of health care and information does not reach that level. The various existing guidelines, including national guidelines, seems not able to improve dyslipidemia therapy to reduce the risk of CVD. The lack of information and participation related to dyslipidemia training seems to prohibit physicians from applying dyslipidemia guidelines, and thus reduces competency in managing dyslipidemic patients in the primary health care or Type C hospitals. ${ }^{15,17,19}$

Most physicians in GP group have less understanding about the adopted dyslipidemia guideline, especially related to the treatment targets. Most physicians in the GP group also did not understand the importance of risk factor management as well as lipid treatment to decrease CVD events. In the internist group, $1.3 \%$ had less understanding about dyslipidemia guideline related to non-drug treatment. Based on a previous survey, it could occur because they think they are too old and too busy to re-learn the guidelines. ${ }^{15,17-19}$ Interestingly, the price of the drugs was not an obstacle to implementing guidelines even in GP group, because most of them used generic medications which is covered by national insurance.

In applying dyslipidemia guidelines, most of the respondents in GP group were still categorized below the standard. Several causes that can be identified were the lack of understanding of the GPs and the lack of patient compliance. In the resident and internist group, the largest barrier in applying the guidelines were the patients lack of education that affect their compliance. ${ }^{18,19}$

This study showed that dyslipidemia guideline application was not spread equally in all physicians. GPs, who have been the frontline in the healthcare system in Indonesia, revealed lack of understanding and application of the guidelines leading to the lack of treatment quality that could raise the CVD events in Indonesia.

Strategies to improve this condition can be divided into each category. The challenge of this study is how to disseminate the information about these guidelines equally in all levels of the healthcare system to raise the scope of CVD prevention. In the GP group, there should be wider spread of information about dyslipidemia training so that the number of participants in dyslipidemia training could improve. This will improve the understanding of dyslipidemia guidelines that may finally improve treatment quality. In the resident and internist group, time and skill of education, consultation, and giving information to different patient levels of education in each visit should be improved. This will establish a patient's trust of the physician and awareness of dyslipidemia treament compliance. ${ }^{15,17-19}$

\section{CONCLUSION}

GPs, as physicians in the primary health care system, had poor information and participation in dyslipidemia training, and poor information of dyslipidemia guidelines (AACE, AHA, CCS), as well as understanding and applying dyslipidemia guidelines (ATP III, PERKENI) into the population. Residents and internists had better perception and application of dyslipidemia guidelines. Strategies for improvement include spreading the information about these guidelines equally in all levels of the healthcare system, and improving time and skill of education, consultation, and giving information to different patient levels of education in each visit, for residents and internists. 


\section{References}

1. Roger VL, Go AS, Lloyd-Jones DM, et al. American Heart Association Statistics Committee and Stroke Statistics Committee. Heart disease and stroke statis $\neg$ tics-2011 update: A report from the American Heart Association. (Errata in: Circulation. 2011;123:e240 and Circulation. 2011;124:e426). 2011;123:e18-e209.

2. Nicholls S, Lundman P. The emerging role of lipoproteins in atherogenesis: Beyond LDL cholesterol. Semin Vasc Med. 2004;4:187195. http://dx.doi.org/10.1055/s-2004-835377.

3. Wild SH, Byrne CD, Tzoulaki I, et al. Metabolic syn $\neg$ drome, haemostatic and inflammatory markers, cerebro $\urcorner$ vascular and peripheral arterial disease: The Edinburgh Artery Study. Atherosclerosis. 2009;203:604-609. http://dx.doi.org/10.1016/ j.atherosclerosis.2008.07.028

4. Rodriguez-Colon SM, Mo J, Duan Y, et al. Metabolic syndrome clusters and the risk of incident stroke: The ath 7 erosclerosis risk in communities (ARIC) study. Stroke. 2009;40:200-205. http://dx.doi.org/10.1161/STROKEAHA.108.523035.

5. Cohen JD, Cziraky MJ, Cai Q, et al. 30-year trends in serum lipids among United States adults: Results from the National Health and Nutrition Examination Surveys II, III, and 1999-2006. (Erratum in: Am J Cardiol. 2010;106: 1826). Am J Cardiol. 2010;106:969-975. http://dx.doi.org/10.1016/j.amjcard.2010.05.030.

6. Jellinger PS, Dickey RA, et al. AACE Lipid Guidelines Committee; The American Association of Clinical Endocrinologists. AACE medical guidelines for clinical practice for the diagnosis and treatment of dyslipidemia and prevention of atherogenesis. (Erratum in: Endocr Pract. 2008;14:802-903). Endocr Pract. 2000;6:162-213.

7. Handelsman Y, Mechanick JI, Blonde L, et al. AACE Task Force for Developing Diabetes Comprehensive Care Plan. American Association of Clinical Endocrinologists Medical Guidelines for Clinical Practice for developing a diabetes mellitus comprehensive care plan. Endocr Pract. 2011;17(Suppl 2):1-53.

8. Summary of the second report of the National Cholesterol Education Program (NCEP) Expert Panel on Detection, Evaluation, and Treatment of High Blood Cholesterol in Adults (Adult Treatment Panel II). JAMA. 1993;269:3015-3023. http://dx.doi.org/10.1001/jama.1993.03500230097036.

9. Mechanick JI, Camacho PM, Cobin RH, et al. American Association of Clinical Endocrinologists Protocol for Standardized Production of Clinical Practice Guidelines--2010 update. Endocr Pract. 2010;16:270283. http://dx.doi.org/10.4158/EP.16.2.270.
10. National Institutes of Health; National Heart Lung, and Blood Institute; 2002 National Cholesterol Education Program. Third report of the National Cholesterol Education Program (NCEP) Expert Panel on detection, evaluation, and treatment of high blood cholesterol in adults (Adult Treatment Panel III): Final Report. NIH Publication No. 02-5215. September 2002

11. Cromwell WC, Otvos JD, Keyes MJ, et al. LDL Particle number and risk of future cardiovascular disease in the Framingham offspring study - implications for LDL man $a$ agement. J Clin Lipidol. 2007;1:583592. http://dx.doi.org/10.1016/j.jacl.2007.10.001.

12. Smith SC Jr, Allen J, Blair SN, et al. AHA/ACC; National Heart, Lung, and Blood Institute. AHA/ACC guidelines for secondary prevention for patients with coronary and other atherosclerotic vascular disease: 2006 update: endorsed by the National Heart, Lung, and Blood Institute. (Erratum in: Circulation. 2006;113:e847.) Circulation. 2006;113:2363-2372.

13. Grundy SM, Cleeman JI, Merz CN, et al. National Heart, Lung, and Blood Institute; American College of Cardiology Foundation; American Heart Association. Implications of recent clinical trials for the National Cholesterol Education Program Adult Treatment Panel III guidelines. Circulation. 2004;110:227-239. http://dx.doi.org/10.1161/01.CIR.0000133317.49796.0E.

14. Lloyd-Jones DM, Wilson PW, Larson MG, et al. Framingham and risk score prediction of lifetime risk for coronary heart disease. Am J Cardiol. 2004;94:20-24. http://dx.doi.org/10.1016/j.amjcard.2004.03.023.

15. Cabana MD, Rand CS, Powe NR, et al. Why don't physicians follow clinical practice guidelines. JAMA. 1999; 282:1458-65. http://dx.doi.org/10.1001/jama.282.15.1458

16. Azwar A. Pengantar administrasi kesehatan. Jakarta: Bina Rupa Aksara. 1996.

17. Schers H, Braspenning J, Drijver R, Wensing M, Grol R. Low back pain in general practice: Reported management and reasons for not adhering to the guidelines in the Netherlands. Br J Gen Pract. 2000; 50:640-644.

18. Schnelle E. The metaplan method: Communication tools for planning and learning groups. Metaplan series No. 7, Hamburg, Quickborn 1979.

19. Wetzel D, Himmel W, Heidenreich R, et al. Participation in a quality of care study and consequences for generalizability of general practice research. Fam Pract. 2005; 22:458-64 http://dx.doi.org/10.1093/fampra/cmi022.

Articles and any other material published in the JAFES represent the work of the author(s) and should not be construed to reflect the opinions of the Editors or the Publisher. Authors are required to accomplish, sign and submit scanned copies of the JAFES Declaration: that the article represents original material, that is not being considered for publication or has not been published or accepted for publication elsewhere. Consent forms, as appropriate, have been secured for the publication of information about patients; otherwise, authors declared that all means have been exhausted for securing such consent. The authors have signed disclosures that there are no financial or other relationships that might lead to a conflict of interest. All authors are required to submit Authorship Certifications that the manuscript has been read and approved by all authors, and that the requirements for authorship have been met by each author. 